\title{
Testosterone modulates platelet aggregation and endothelial cell growth through nitric oxide pathway
}

\author{
Adrián E Campelo ${ }^{1,2}$, Pablo H Cutini ${ }^{1,2}$ and Virginia L Massheimer ${ }^{1,2}$ \\ ${ }^{1}$ Cátedra de Bioquímica Clínica II, Departamento de Biología, Bioquímica y Farmacia, Universidad Nacional del Sur, San Juan 670, B8000ICN Bahía Blanca, \\ Argentina \\ ${ }^{2}$ Consejo Nacional de Investigaciones Científicas y Técnicas (CONICET), Buenos Aires, Argentina \\ (Correspondence should be addressed to V L Massheimer at Cátedra de Bioquímica Clínica II, Departamento de Biología, Bioquímica y Farmacia, Universidad \\ Nacional del Sur; Email: massheim@uns.edu.ar)
}

\begin{abstract}
The aim of the present study was to investigate the effect of testosterone on the modulation of cellular events associated with vascular homeostasis. In rat aortic strips, 5-20 min treatment with physiological concentrations of testosterone significantly increased nitric oxide (NO) production. The rapid action of the steroid was suppressed by the presence of an androgen receptor antagonist (flutamide). We obtained evidence that the enhancement in NO synthesis was dependent on the influx of calcium from extracellular medium, because in the presence of a calcium channel blocker (verapamil) the effect of testosterone was reduced. Using endothelial cell (EC) cultures, we demonstrated that androgen directly acts at the endothelial level. Chelerythrine or PD98059 compound completely suppressed the increase in $\mathrm{NO}$ production, suggesting that the mechanism of action of
\end{abstract}

the steroid involves protein kinase $\mathrm{C}$ and mitogen-activated protein kinase pathways. It is known that endothelial $\mathrm{NO}$ released into the vascular lumen serves as an inhibitor of platelet activation and aggregation. We showed that testosterone inhibited platelet aggregation and this effect was dependent on endothelial NO synthesis. Indeed, the enhancement of NO production elicited by androgen was associated with EC growth. The steroid significantly increased DNA synthesis after $24 \mathrm{~h}$ of treatment, and this mitogenic action was blunted in the presence of NO synthase inhibitor $N$-nitro-L-arginine methyl ester. In summary, testosterone modulates vascular EC growth and platelet aggregation through its direct action on endothelial NO production.

Journal of Endocrinology (2012) 213, 77-87

\section{Introduction}

The clinical observation that premenopausal women have lower incidences of cardiovascular disease (CVD) than age-matched men and postmenopausal women suggests that ovarian hormones have a protective effect on the cardiovascular system (Farhat et al. 1996). A great deal of evidence from observational and experimental studies, in both animals and humans, supports the concept of a protective effect of estrogens on the cardiovascular system (Koledova \& Khalil 2007). Thus, it was wholly unexpected when the Women's Health Initiative, a large-scale trial of hormone replacement therapy (HRT) in postmenopausal women, was terminated early due to a surprising increase in the incidence of cardiovascular events (Hsia et al. 2006). The risk/benefit of HRT for prevention of CVD is still controversial (Ouyang et al. 2006).

The menopausal transition involves a progressive decline in ovarian steroidogenesis capacity. Beyond menopause, although the plasmatic levels of estradiol $\left(\mathrm{E}_{2}\right)$ have a marked drop, the ovarian synthesis of androgens and progestins is also affected (Qiao et al. 2008). This is why during menopause, the contribution of sex steroids in the regulation of vascular homeostasis is altered. Based on this, it is proposed that the higher incidence of CVD observed in postmenopausal women could be due not only to alterations in cellular and molecular actions of $E_{2}$, but also suitable to changes in the contribution of androgens to vascular behavior regulation. In females, the vascular effects of $E_{2}$ have been extensively investigated and characterized (Miller \& Duckles 2008), whereas androgens have received less attention. Therefore, the improvement in the knowledge of testosterone vascular action would be useful to for a better understanding of postmenopausal vascular pathology.

Vascular homeostasis mainly depends on the tight control of endothelial cell (EC) and smooth muscle cell functions and the regulation of the interactions between blood cells (platelets and monocytes) and vascular cells (Villar et al. 2008). Vascular endothelium plays a critical role in the maintenance of antiatherogenic and antithrombotic 
properties of blood vessels. Besides acting as a selective diffusion barrier, endothelium allows the integration of hormonal and nutritional signals present in blood, their transduction toward the underlying smooth muscle layer, and the regulation of vascular tone. This is achieved by the secretion of biochemical factors such as nitric oxide (NO), prostacyclin, and endothelin-1. In addition, endothelium modulates platelet aggregation, leukocyte adhesion and transendothelization, and muscle cell migration (Moncada \& Higgs 2006, Miller \& Mulvagh 2007). Under vascular injury, this control function can be lost, a fact that conducts to endothelium dysfunction and development of atherosclerosis, vascular diseases, and aging (Cooke \& Dzau 1997). EC proliferation is particularly important in vascular repair following injury. When the endothelial layer is damaged, vessel repair is achieved by migration and proliferation of adjacent ECs (Moreno et al. 2009).

$\mathrm{NO}$ is the main regulator of vascular homeostasis and protects the vasculature against thrombosis and atherosclerosis. Endothelial NO promotes blood vessel relaxation, prevents platelet aggregation and blood cell adhesion to endothelial surface, and decreases the expression of proinflammatory genes (Ignarro 1989, Harrison et al. 2006). $\mathrm{NO}$ is synthesised by the enzyme NO synthase (NOS), through the conversion of L-arginine to L-citrulline (Förstermann 2010). In vascular tissue, distinct isoforms of NOS have been identified: constitutive NOS (cNOS), inducible NOS (iNOS; Knowles \& Moncada 1994), and neuronal NOS (nNOS; White et al. 2005). cNOS is expressed in ECs (eNOS; Liu et al. 1997) and its activation is calcium and calmodulin dependent (Förstermann 2010), whereas iNOS is located in vascular smooth muscle cells (VSMCs) and its expression is regulated by cytokines and endotoxins (Kanno et al. 1994). Type 1 nNOS has been recently identified as a predominant isoform expressed in porcine and human coronary artery smooth muscle (White et al. 2005), and it has been proposed that $\mathrm{E}_{2}$ relaxes coronary artery not only by targeting eNOS but also by increasing $\mathrm{NO}$ production in smooth muscle cells via nNOS activation (Han et al. 2007).

The androgen receptor (AR) has been identified in vascular cells (Liu et al. 2003), and recent reports show that this receptor mediates a variety of actions of androgens in ECs and VSMCs (Li \& Al-Azzawi 2009).

Several studies have established that androgens induce vasorelaxation. Physiological to pharmacological concentrations $(100 \mathrm{pM}-10 \mu \mathrm{M})$ of testosterone promote vasodilatation with dual mechanism. At lower concentrations the effect is endothelium dependent, whereas the vasorelaxation induced by pharmacological concentrations $(>100 \mu \mathrm{M})$ appears to be endothelium independent (Perusquía \& Stallone 2010). Indeed, it has been reported that in ECs from human umbilical vein testosterone regulates cellular growth and apoptosis (Ling et al. 2002) and attenuates the tumor necrosis factor $\alpha$ (TNF $\alpha)$-induced expression of the atherogenic vascular cell adhesion molecule-1 (Mukherjee et al. 2002).
On the other hand, it has been reported that dehydroepiandrostenedione (DHEA) stimulates EC proliferation and angiogenesis through a rapid mechanism mediated by pertussis toxin (PTX)-sensitive $\mathrm{G}$ proteins and ERK1/2 pathways (Liu et al. 2008). Moreover, other authors demonstrated that DHEA triggers NO synthesis due to an enhanced expression of eNOS and additionally through a nongenomic stimulation of enzyme activity (Simoncini et al. 2003).

In this study, we investigated the effect of testosterone on the modulation of cellular events associated with vascular homeostasis such as vasoactive production, cell growth, and platelet aggregation. Moreover, the molecular mechanism of action of the steroid was also evaluated.

\section{Materials and Methods}

\section{Materials}

$\left[{ }^{3} \mathrm{H}\right]$-Thymidine was purchased from New England Nuclear (Chicago, IL, USA). Griess reagents were purchased from Britania Laboratories (Buenos Aires, Argentina). Trypsin/EDTA $(10 \times)$, L-glutamine, amphotericin B, penicillin/streptomycin, and fetal bovine serum (FBS) were obtained from PAA Laboratories (Pasching, Austria). PD98059, chelerythrine, testosterone, $\mathrm{N}$-nitro-L-arginine methyl ester (L-NAME), flutamide, DMEM, and all other reagents were purchased from Sigma Chemical Co.

\section{Animals}

Sexually mature female Wistar rats (4-7 months old) that had progressed through at least three consecutive estrous cycles were fed with standard rat food, given water ad libitum, and maintained on a $12 \mathrm{~h}$ light: $12 \mathrm{~h}$ darkness cycle. The estrous cycle activity was evaluated by optical microscopic examination of vaginal smears, and the animals chosen for the experimental design were those with similar cycle length and the same number of days spent at each stage of the cycle. All animal work was performed at the Unit of Animal Care belonging to the Biology, Biochemistry, and Pharmacy Department of the University. The Animal Care Use Committee approved the protocol used.

\section{Rat aortic strips preparation}

Rat aortic strips (RAS) were obtained as previously described (Selles et al. 2005). Briefly, animals were killed by cervical dislocation and the thoracic aorta was immediately removed and placed in cold Dulbecco's PBS, cleaned of adherent connective tissue, and cut into $1 \cdot 5-\mathrm{mm}$ strips. Special care was taken to avoid contact with luminal surface in order to preserve the endothelial integrity. The strips were placed in the incubation medium: $145 \mathrm{mM} \mathrm{NaCl}, 5 \mathrm{mM} \mathrm{KCl}$, $1.2 \mathrm{mM} \mathrm{MgSO}_{4}, 1 \mathrm{mM} \mathrm{CaCl}, 10 \mathrm{mM}$ glucose, $10 \mathrm{mM}$ HEPES, pH 7.35, and pre-equilibrated for $10 \mathrm{~min}$ at $37^{\circ} \mathrm{C}$ in 
a shaking thermostatized water bath. In vitro treatments were performed by incubation of RAS with the hormone for short time intervals. Control groups received vehicle alone (isopropanol $<0 \cdot 1 \%, v / v$ ). When antagonist compounds (flutamide, verapamil) were employed, they were added to the incubation medium $30 \mathrm{~min}$ before the treatment.

\section{EC cultures}

EC cultures were obtained from aortic ring explants isolated from young Wistar female rats (3-5 weeks old) as previously described (Cutini et al. 2009). Briefly, the full length thoracic aorta was aseptically removed and then cut into ring segments $(1 \mathrm{~mm})$. Ring explants were seeded in 60-mm matrix-coated Petri dishes (NUNC, Rochester, NY, USA) containing phenol red-free DMEM supplemented with 10\% (v/v) FBS, $3.7 \mathrm{mg}$ sodium bicarbonate, $60 \mu \mathrm{g} / \mathrm{ml}$ penicillin, $100 \mu \mathrm{g} / \mathrm{ml}$ streptomycin, $2.5 \mu \mathrm{g} / \mathrm{ml}$ amphotericin $\mathrm{B}$, and $2 \mathrm{mM}$ L-glutamine and were incubated at $37^{\circ} \mathrm{C}$ in $5 \% \mathrm{CO}_{2}$ atmosphere. After 5 days of culture, ring explants were removed and the remaining cells were allowed to reach confluence. The identity of the ECs was determined by a) phase contrast microscopic observation of the characteristic morphology of cobblestone shape growth in confluent monolayer, b) the positive immunocytochemistry reactivity to factor VIII and to anti-Vimentin, clone V9 using DakoCytomation EnVision system, and c) the bioability to synthesize NO (Bachetti \& Morbidelli 2000). Cells from passages $2-7$ were used for all experiments.

\section{Measurement of NO production}

RAS were treated as indicated previously and nitrites $\left(\mathrm{NO}_{2}^{-}\right)$ were measured in the incubation media as a stable and nonvolatile breakdown product of the NO released, employing the spectrometric Griess reaction (Cutini et al. 2009). Briefly, aliquots of incubation medium were mixed with Griess reagent ( $1 \%$ sulfanilamide and $0 \cdot 1 \%$ naphthalenediamine dihydrochloride in $2 \cdot 5 \%(\mathrm{v} / \mathrm{v})$ phosphoric acid) and were incubated for $10 \mathrm{~min}$ at room temperature. When ECs were used, cells were seeded on 24-multiwell culture plates (NUNC) at a density of $3.5 \times 10^{4}$ cells/well and allowed to grow to $90 \%$ of confluence in DMEM containing $10 \%$ (v/v) FBS. When compounds chelerythrine, PD98059 and cycloheximide were used, they were added $1 \mathrm{~h}$ before the hormonal treatment. After respective hormonal treatment in fresh DMEM containing 1\% (v/v) FBS, aliquots of culture medium supernatant were mixed with Griess reagent and incubated for $10 \mathrm{~min}$ at room temperature. Absorbance was measured at $548 \mathrm{~nm}$ in a Hitachi U-1000 spectrophotometer. The concentration of nitrite in the samples was determined with reference to a sodium nitrite standard curve performed in the same matrix. The aortic strips and cells were then dissolved in $1 \mathrm{M} \mathrm{NaOH}$ and aliquots were taken for protein determination by Lowry's method (Lowry et al. 1951). Results were expressed as nanomolar of NO per milligram of protein.

\section{$\left.{ }^{3} \mathrm{H}\right]$-Thymidine incorporation assay}

ECs were seeded on 24-multiwell culture plates (NUNC) at a density of $3 \times 10^{4}$ cells/well in DMEM supplemented with $10 \%$ (v/v) FBS and allowed to grow to $60-70 \%$ of confluence. The cells were made quiescent by placing in serum-free DMEM for $24 \mathrm{~h}$ and further exposed to different concentrations of testosterone or vehicle control (isopropanol $<0 \cdot 1 \%, \mathrm{v} / \mathrm{v})$, for $24 \mathrm{~h}$ in fresh DMEM containing $1 \%(\mathrm{v} / \mathrm{v})$ FBS. The cells were pulsed with $1 \mu \mathrm{Ci} / \mathrm{ml}$ of $\left[{ }^{3} \mathrm{H}\right]$-thymidine during the last $2 \mathrm{~h}$ of treatment. Cells were rinsed twice with PBS to remove the unincorporated $\left[{ }^{3} \mathrm{H}\right]$-thymidine. Ice-cold trichloroacetic acid $(10 \%, \mathrm{v} / \mathrm{v})$ was added and the acid-insoluble material was dissolved with $1 \mathrm{M}$ $\mathrm{NaOH}$. Radioactivity was measured by liquid scintillation using a Wallac1414 counter. The protein concentrations were determined by Lowry's method and the results were expressed as counts per minute per milligram of protein (Cutini et al. 2009).

\section{Platelet aggregation assay}

Platelet aggregation was measured using a turbidimetric assay as previously described (Polini et al. 2007). ECs were seeded on 24-multiwell culture plates (NUNC) at a density of $3 \times 10^{4}$ cells/well in DMEM supplemented with $10 \%(\mathrm{v} / \mathrm{v})$ FBS and allowed to grow to $60-70 \%$ of confluence. Culture medium was replaced by $400 \mu \mathrm{l}$ of platelet-rich plasma (PRP, $3 \times 10^{8}$ platelets $/ \mathrm{ml}$ ) and exposed to testosterone for 1-10 min. Immediately after the treatment, $285 \mu \mathrm{l}$ of PRP was taken and set in a CronoLog 430 aggregometer cubette with continuous stirring. Aggregation was initiated by the addition of $2 \times 10^{-5} \mathrm{M}$ ADP. Control group containing ECs in PRP was treated with vehicle alone (isopropanol $<0 \cdot 1 \%, \mathrm{v} / \mathrm{v}) ; 60$ units $/ \mathrm{ml}$ of super oxide dismutase was added to the incubation medium before the hormonal treatment in order to prevent NO degradation (Gryglewski et al. 1986). When L-NAME compound was used, it was added to the incubation medium $30 \mathrm{~min}$ prior to hormonal treatment. Changes in light transmission were recorded for $5 \mathrm{~min}$ after ADP addition. The signal generated in platelet-poor plasma was taken as $100 \%$ transparent control (Kikuta et al. 1998). ECs were dissolved in $1 \mathrm{M} \mathrm{NaOH}$ and aliquots were taken for protein determination by Lowry's method. Results were expressed as percent inhibition of platelet aggregation per milligram of protein. The maximal platelet aggregation was considered to be that induced by the control samples. Two or three animals were used for each experiment.

\section{EC migration assay}

ECs were seeded at a density of $5 \times 10^{5}$ cells $/ \mathrm{cm}^{2}$ in $60-\mathrm{mm}$ NUNC dishes with DMEM containing $10 \%$ FBS and grown to $90 \%$ of confluence. Cells were starved for $24 \mathrm{~h}$ in serumfree medium. In order to evaluate EC migration a wound was made by pressing a razor blade down on the dish to cut the cell 
layer. The blade was then gently moved to one side to remove part of the monolayer. Immediately, the detached cells were washed twice with PBS and cultured in fresh DMEM containing 1\% FBS plus testosterone or vehicle control. After $24 \mathrm{~h}$ of culture, cells were fixed in 4\% paraformaldehyde and stained with Giemsa. Migration was quantified by counting the number of cell nuclei that migrated at the scratched area in at least seven different microscopic fields representative of each culture plate. EC migration was recorded using an OLYMPUS C7070WZ optical microscope system. Results were expressed as means $\underline{ \pm}$ s.D. of number of migrated cells/field (Sandoval et al. 2010).

\section{Statistical analysis}

Each experimental condition has been reproduced in at least three independent experiments performed by quadruplicate. All data are presented as mean \pm s.D. Comparisons between two means were made using Student's $t$-test and multiple comparisons with one-way or two-way ANOVA, followed by Fisher least significant difference test. Differences at $P<0 \cdot 05$ were considered significant.

\section{Results}

Using RAS, we studied the effect of testosterone on $\mathrm{NO}$ production. Figure 1 shows the time course of $\mathrm{NO}$ synthesis induced by treatment with $1 \mathrm{nM}$ testosterone.

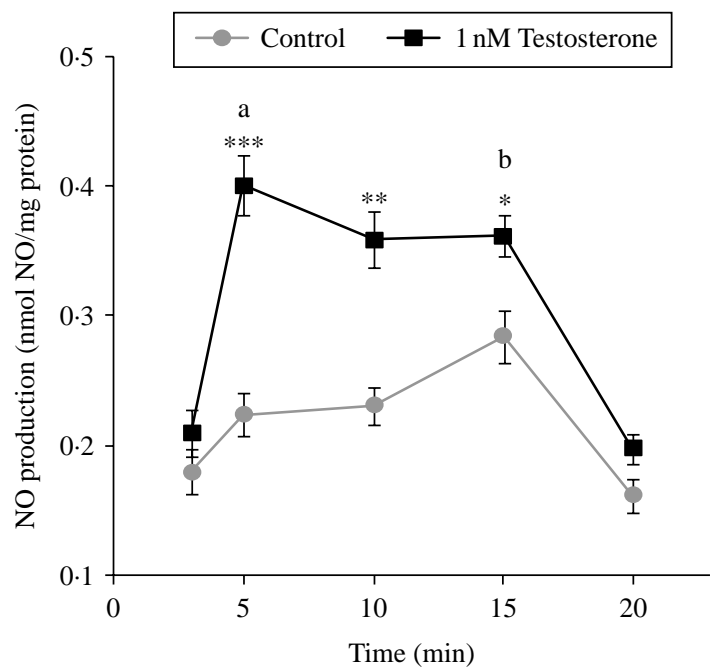

Figure 1 Time course profile of the effect of testosterone on NO production in RAS. RAS were exposed to $1 \mathrm{nM}$ testosterone at the time indicated. Controls to each time point were also performed. NO production was measured as described in Materials and Methods section. Results are the average \pm s.D. of three independent experiments performed by quadruplicate. ${ }^{*} P<0 \cdot 05,{ }^{* *} P<0 \cdot 01$, ${ }^{* * *} P<0.001$ with respect to each control, ${ }^{\mathrm{a}} P<0.05$ ( 3 vs $5 \mathrm{~min}$ testosterone treatment), and ${ }^{\mathrm{b}} P<0.05$ (15 vs 20 min testosterone treatment).

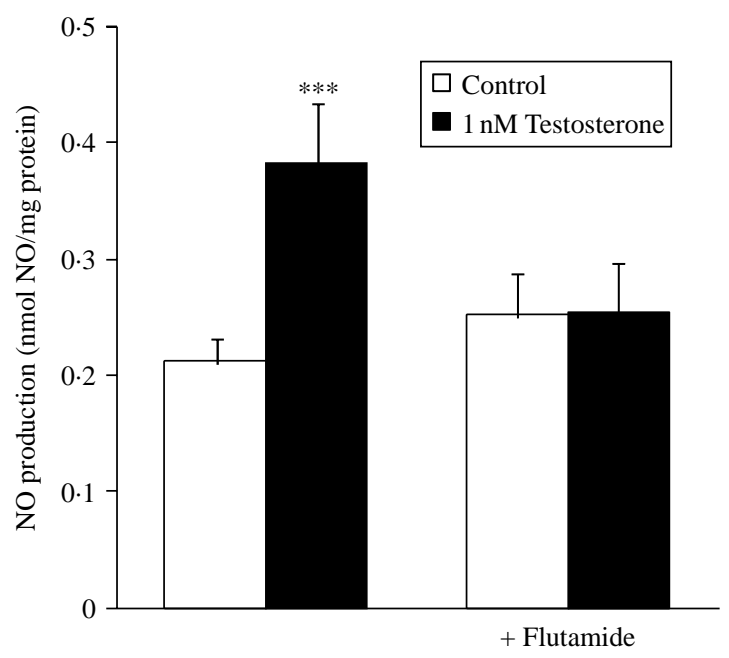

Figure 2 Effect of flutamide on NO synthesis induced by testosterone. RAS were preincubated in the absence or presence of $10 \mathrm{nM}$ flutamide for $30 \mathrm{~min}$ and then exposed to $1 \mathrm{nM}$ testosterone for $5 \mathrm{~min}$. NO production was measured as described in Materials and Methods section. Results are the average \pm s.D. of three independent experiments performed by quadruplicate. *** $P<0 \cdot 001$ with respect to control.

NO production was markedly enhanced after $5 \mathrm{~min}$ of exposure to the hormone $(79 \%$ above control, $P<0 \cdot 01)$. This incremental increase was sustained for $15 \mathrm{~min}$ and returned to baseline at $20 \mathrm{~min}$ of hormonal treatment.

To test whether the enhancement of NO production induced by testosterone involved the participation of the AR, RAS were preincubated with the AR antagonist flutamide for $30 \mathrm{~min}$ and then exposed to $1 \mathrm{nM}$ testosterone for an additional $5 \mathrm{~min}$. As can be observed in Fig. 2, the presence of the antagonist $(10 \mathrm{nM})$ completely suppressed the testosteroneinduced stimulation in NO synthesis. Similar results were obtained with $100 \mathrm{nM}$ flutamide (data not shown).

Considering that the activity of some members of the NOS family is regulated by calcium, we studied the role of extracellular calcium in the stimulation of NO production elicited by testosterone treatment. For this purpose, RAS were treated with the hormone in a calcium-free medium (plus $1 \mathrm{mM}$ EGTA). Figure 3 shows that the increase in NO production induced by $1 \mathrm{nM}$ testosterone was reduced in the absence of calcium in the incubation medium ( 80 vs $26 \%$ above control, testosterone vs testosterone+EGTA). Furthermore, the role of extracellular calcium was evaluated using a calcium channel blocker. When the influx of calcium was blocked by the presence of $10^{-4} \mathrm{M}$ verapamil, similar results were obtained ( 80 vs $28 \%$ above control, testosterone vs testosterone+verapamil). These data suggest that the stimulatory action of testosterone on NOS activity is dependent in part on the influx of calcium from the extracellular medium.

RAS represent an experimental system that contains ECs, VSMCs and fibroblasts. To study whether androgen exerts a 


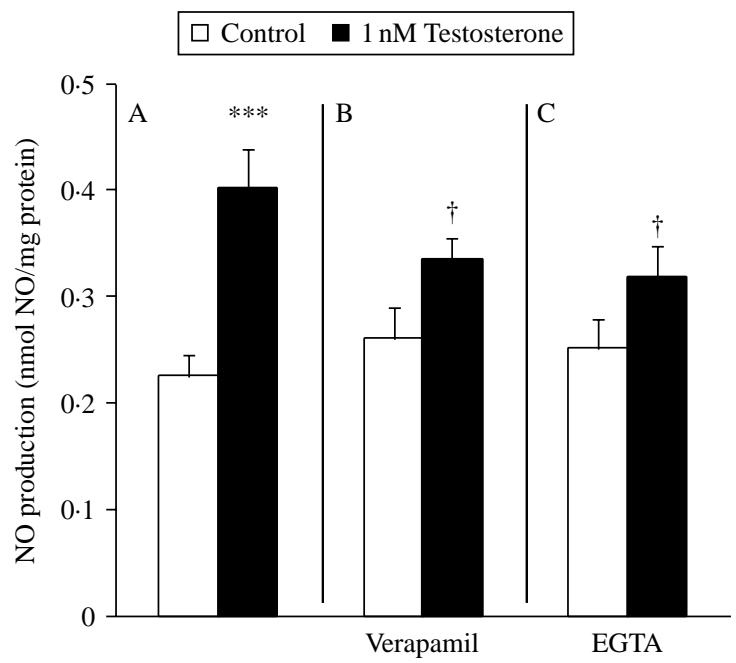

Figure 3 Study of the effect of extracellular calcium on testosteroneinduced $\mathrm{NO}$ synthesis. (A and $\mathrm{B}$ ) RAS were placed in the incubation medium containing $1 \mathrm{mM} \mathrm{CaCl}_{2}$ in the presence or absence of $100 \mu \mathrm{M}$ verapamil and then exposed to $1 \mathrm{nM}$ testosterone for $5 \mathrm{~min}$. (C) RAS were incubated in a calcium-free medium plus $1 \mathrm{mM}$ EGTA and treated with $1 \mathrm{nM}$ testosterone or vehicle for $5 \mathrm{~min}$. $\mathrm{NO}$ production was measured as described in Materials and Methods section. Results are the average \pm s.D. of three independent experiments $(n=5)$. ${ }^{* * *} P<0.001$ with respect to control and ${ }^{+} P<0 \cdot 05$ with respect to testosterone.

direct action at the endothelial level, we performed EC cultures and measured the effect of the steroid on endothelial NO production. These data are presented in Table 1. As can be observed, the hormone induced a very fast stimulation of endothelial NO synthesis. The time course profile, elicited by testosterone in isolated EC, does not exhibit the drop in NO production observed in RAS after 20 min treatment. The enhancement in the vasoactive production was sustained along the whole time interval. Figure 4 shows that this stimulatory action was exhibited at physiological concentrations $(0 \cdot 1-1 \mathrm{nM})$.

Having found that testosterone stimulates NO synthesis via its direct action on ECs, we continued with the study of the mechanism of steroid action. Owing to the fact that the hormonal effect on NO synthesis occurred in a very short time of treatment, we evaluated whether the steroid produces its biochemical action in a nongenomic manner, independent of gene transcription. To that end, we measured NO production in ECs in the presence of cycloheximide, an inhibitor of protein synthesis. Figure 5 shows that the increase in NO production induced by testosterone was not affected by the presence of cycloheximide, suggesting the nongenomic feature of this effect. Bearing in mind that eNOS is regulated by phosphorylation, we evaluated whether the protein kinase $\mathrm{C}$ (PKC) system would modulate the hormonal action of testosterone on NO production. For this purpose, we chose chelerythrine as the PKC inhibitor. Preincubation of ECs with $0.5 \mu \mathrm{M}$ chelerythrine completely suppressed the enhancement in NO synthesis induced by $5 \mathrm{~min}$ of treatment with $1 \mathrm{nM}$ testosterone (Fig. 5). Similar results were obtained using $0 \cdot 2$ or $1 \mu \mathrm{M}$ chelerythrine. We also tested the effect of the mitogen-activated protein kinase (MAPK) signaling cascade on the hormonal regulation of the vasoactive synthesis. As can be seen in Fig. 5, the hormonal stimulation of NO production was blunted by the presence of the MEK inhibitor, PD98059 (1 $\mu \mathrm{M})$.

It is known that when endothelial NO is released into the vascular lumen it serves as a modulator of platelet activation, inducing an inhibition of platelet aggregation. We tested the effect of androgen on vascular-dependent platelet aggregation. ECs were incubated with PRP and subsequently exposed to testosterone treatment for 1-10 min. Immediately, aliquots of PRP were transferred to the aggregometer and ADP-induced platelet aggregation was registered. Figure 6A shows a representative profile of the aggregation process corresponding to basal (PRP without ECs), control (ECs in PRP with vehicle alone), and testosterone (ECs plus PRP plus testosterone). Maximal aggregation was determined under basal conditions, and the aggregation process decreased progressively in control and hormonal groups. These data showed that the steroid exhibits an antiaggregatory effect compared to control group. Table 2 shows the quantitative data of the dose-response study $(0 \cdot 01-10 \mathrm{nM})$. As can be observed, androgen exhibited a significant antiaggregatory action at all doses tested. Table 2 also shows that a direct effect of testosterone on platelet aggregation was ruled out, since the addition of testosterone to PRP in the absence of ECs induced maximal aggregation similar to the basal group. Afterward, we tested whether NO mediates the antiaggegatory effect of the steroid. To that end, ECs were preincubated with L-NAME, a NOS-specific inhibitor, followed by the addition of PRP and steroid treatment. The inhibition of platelet aggregation induced by the hormone was partially

Table 1 Rapid action of testosterone on endothelial nitric oxide production

NO production $(\mathrm{nmol} / \mathrm{mg} \text { protein })^{\mathrm{a}}$

\begin{tabular}{|c|c|c|c|c|c|}
\hline Treatment & $3 \mathrm{~min}$ & $5 \mathrm{~min}$ & $10 \mathrm{~min}$ & $15 \mathrm{~min}$ & $20 \mathrm{~min}$ \\
\hline Control & $5 \cdot 17 \pm 0 \cdot 97$ & $4 \cdot 25 \pm 1 \cdot 10$ & $4 \cdot 50 \pm 0 \cdot 83$ & $5 \cdot 05 \pm 0 \cdot 91$ & $4.97 \pm 0.99$ \\
\hline $1 \mathrm{nM}$ testosterone & $8 \cdot 37 \pm 0.88^{\dagger}$ & $6 \cdot 90 \pm 0.60^{+}$ & $7 \cdot 38 \pm 0 \cdot 70^{\dagger}$ & $7 \cdot 92 \pm 1 \cdot 20^{*}$ & $7 \cdot 25 \pm 1 \cdot 11^{*}$ \\
\hline
\end{tabular}

${ }^{*} P<0 \cdot 05$ with respect to each control; ${ }^{\dagger} P<0 \cdot 01$ with respect to each control.

${ }^{a} \mathrm{EC}$ were incubated with $1 \mathrm{nM}$ testosterone at the indicated times. NO production was measured as described. Results represent the average \pm s.D. of three independent experiments $(n=5)$. 


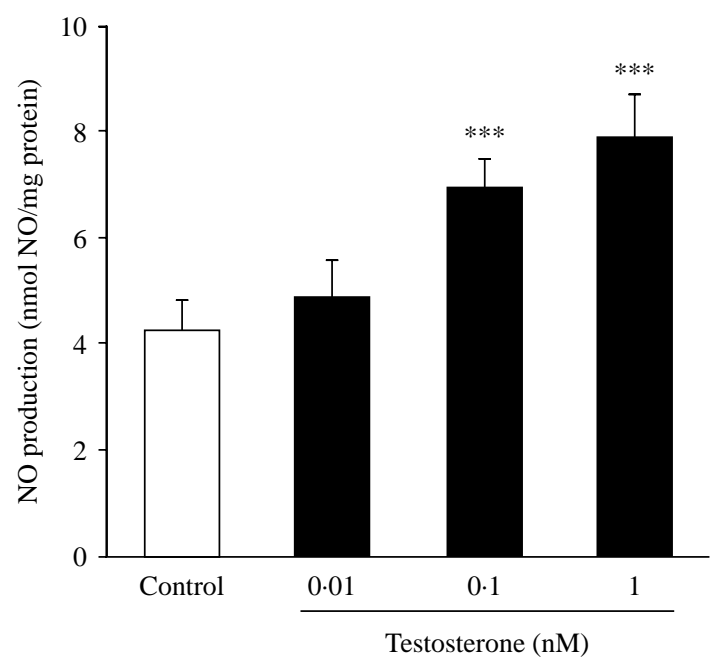

Figure 4 Stimulation of endothelial NO production by testosterone: dose-response profile. ECs cultured in the presence of FBS $1 \%(\mathrm{v} / \mathrm{v})$ were incubated with testosterone at the indicated concentrations for $5 \mathrm{~min}$. NO production was measured as described in Materials and Methods section. Results are the average \pm s.D. of four independent experiments $(n=4)$. ${ }^{* * *} P<0 \cdot 001$ with respect to control.

suppressed in the presence of NOS inhibitor, suggesting that the antiaggregatory action of androgen is dependent on the release of NO from ECs (Fig. 6B).

It has been proposed that NO modulates vascular cell growth (Villalobo 2006). Using $\left[^{3} \mathrm{H}\right]$-thymidine incorporation assay, we studied the effect of testosterone on EC proliferation. Synchronized cultures were exposed to $1 \mathrm{nM}$ testosterone for different times of treatment. The steroid significantly increased DNA synthesis after $24 \mathrm{~h}$ of treatment (44\% above control, $P<0 \cdot 05)$; in contrast, no statistical differences among control and treated groups were observed after 12,36 , or $48 \mathrm{~h}$ of treatment (Fig. 7). The mitogenic action of testosterone was blunted by the presence of the NOS inhibitor L-NAME, suggesting that the action of testosterone depends on NO generation (Fig. 8).

Finally, in order to assess the role of testosterone on cell migration, wounding assays were performed. Figure 9 shows a microphotography representative of these assays. We found that $10 \mathrm{nM}$ testosterone enhances cell migration compared to nontreated cells. As can be observed, the number of cells/field in the denuded area in the monolayers exposed to $24 \mathrm{~h}$ treatment with the steroid was higher with respect to control group.

\section{Discussion}

The results presented in this work provide evidence linking testosterone's effect on endothelial NO production with the hormonal modulation of platelet aggregation and EC growth. Physiological concentrations of testosterone stimulate EC growth and inhibit platelet aggregation, through its direct action on endothelial NO production. The molecular mechanism of action elicited by testosterone involves a nongenomic stimulation of NO synthesis, which depends on calcium influx from the extracellular medium and on MAPK and PKC pathways.

Endothelial NO bioavailability can be modified by a plethora of hormones and factors (Duckles \& Miller 2010). eNOS activity is regulated by changes in intracellular calcium and phosphorylation. After agonist stimulation, the enhancement in cytosolic calcium levels leads to calmodulin binding to eNOS and subsequent phosphorylation. The enzymes responsible for phosphorylation depend on the primary stimulus. Several intracellular transduction cascades, such as PI3K/AKT, AC/PKA, CaMKII, PLC/PKC, and MAPK, have been involved in the hormonal regulation of eNOS activity (Förstermann 2010).

In this work we found that in rat aortic tissue, NO production is suitable to be regulated by testosterone. Physiological concentrations of testosterone stimulate NO production, with marked increases after a few minutes of treatment falling to control values at $20 \mathrm{~min}$. This temporal profile would be the result of the participation of diverse signal transduction pathways that conduct to activation or inhibition of NOS. Nevertheless, when isolated ECs were used, the stimulatory action of the steroid was sustained, with a slight decrease in NO production at $20 \mathrm{~min}$. In view of this fact, we suppose the difference in the temporal profile exhibited by testosterone in RAS and ECs would be due the presence of smooth muscle cells in intact aortic tissue. Moreover, the results obtained using isolated ECs support the

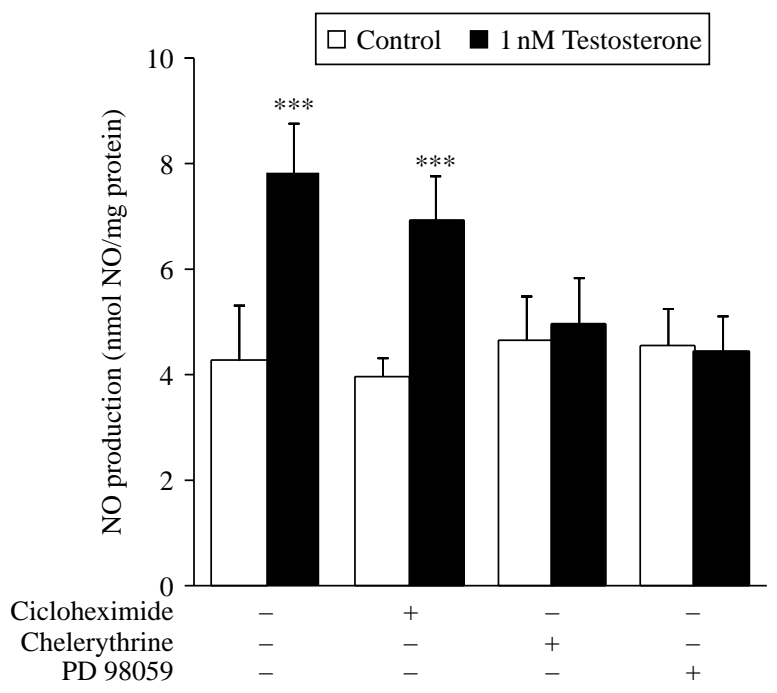

Figure 5 Characterization of the rapid action of testosterone on endothelial NO production. ECs cultured in the presence of FBS $1 \%(\mathrm{v} / \mathrm{v})$ were preincubated with $100 \mu \mathrm{M}$ cycloheximide, $1 \mu \mathrm{M}$ chelerythrine, or $1 \mu \mathrm{M}$ PD98059 for $1 \mathrm{~h}$ and then treated with $1 \mathrm{nM}$ testosterone for $5 \mathrm{~min}$. NO production was measured as described in Materials and Methods section. Results are the average \pm s.D. of three independent experiments $(n=5)$. $* * * P<0 \cdot 001$ with respect to each control. 
A

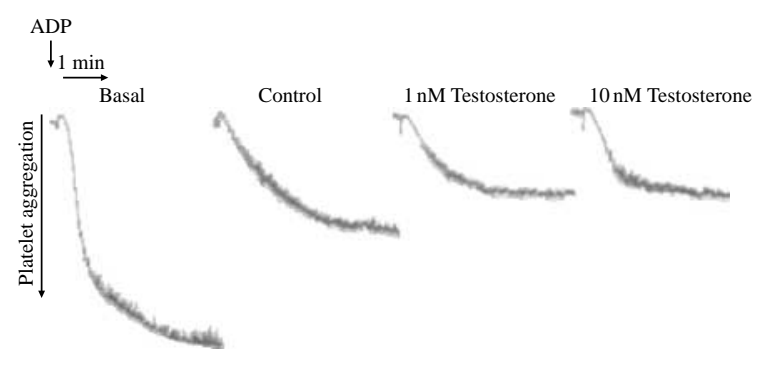

B

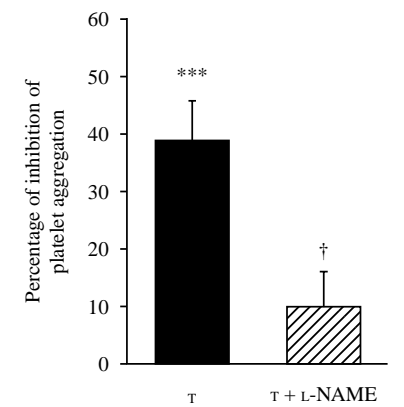

Figure 6 Effect of testosterone on ADP-induced platelet aggregation. (A) Representative profile of aggregation process: ECs were incubated for $1 \mathrm{~min}$ in PRP with the addition of testosterone (1-10 nM) or vehicle alone (control). PRP was quickly removed and platelet aggregation was initiated by the addition of ADP (arrow). (B) ECs were preincubated with or without L-NAME and then exposed to testosterone. Results are expressed as percentage of inhibition of platelet aggregation with respect to control group and represents the mean \pm S.D. of three independent experiments $(n=5) .{ }^{* * *} P<0.001$ with respect to control, ${ }^{+} P<0.05$ with respect to testosterone.

hypothesis of a direct action of androgen at the endothelial level. Evidence reported in the literature shows that testosterone induces vasorelaxation from physiological to pharmacological concentrations. The vasorelaxation induced by low concentrations of androgen appears to be dependent on endothelial NO synthesis (Rowell et al. 2009), whereas higher concentrations are associated with a direct action on vascular muscle cells. Our results provide evidence of a direct action of a low concentration of testosterone on endothelial NO production. When the molecular basis of this effect was studied, we found that the stimulatory action of androgen on NO generation was dependent, at least in part, on the influx of calcium from the extracellular medium. Furthermore, we obtained evidence of the participation of $A R$ in the rapid action of the steroid in NO production. When AR was antagonized by the presence of flutamide, the effect of androgen was blunted. These findings agree with those reported by other authors that involve the participation of AR in the nongenomic action of testosterone on eNOS activation in ECs of umbilical vein (Goglia et al. 2010). However, several reports show that the vasorelaxation action of testosterone in male arteries is AR independent (Tep-areenan et al. 2002). In fact, some of these studies have used supraphysiological concentrations of testosterone. In male coronary and pulmonary arteries, 1-1000 $\mu \mathrm{M}$ testosterone induced vasodilatation independent of $\mathrm{AR}$ and $\mathrm{NO}$ participation (Jones et al. 2002, 2004). On the other hand, and in agreement with our observations, Yu et al. (2010) recently showed that in male human aortic ECs, physiological concentrations of testosterone $(1-100 \mathrm{nM})$ rapidly increase NO production via AR activation of eNOS. Perhaps, the discrepancies between the past and the present findings would be attributed to gender differences, cellular selectivity of androgen action, and/or steroid concentrations.

Following with the study of the mechanism of action of testosterone, using cycloheximide as a protein synthesis inhibitor, we confirmed the nongenomic feature of steroid action. The rapid stimulation of NO production was not affected by the presence of the inhibitor. Nongenomic action of steroid hormones has been extensively associated with hormonal activation of signal transduction pathways (Falkenstein et al. 2000). Therefore, we evaluated the participation of signaling cascades in the effect of testosterone on endothelial NO generation. The results obtained using the compounds PD98059 and chelerythrine as inhibitors of MEK and PKC, respectively, suggest that MAPK and PKC might be

Table 2 Effect of testosterone on platelet aggregation

\begin{tabular}{|c|c|c|}
\hline Treatment & $\begin{array}{l}\text { Percentage of inhibition } \\
\text { of platelet aggregation } \\
\text { with respect to control }\end{array}$ & $\begin{array}{l}\text { Percentage of platelet } \\
\text { aggregation with } \\
\text { respect to basal }^{\mathrm{b}}\end{array}$ \\
\hline $10^{-11} \mathrm{M}$ testosterone & $21 \cdot 2 \pm 5 \cdot 3 *$ & $98 \pm 4 \cdot 9$ \\
\hline $10^{-10} \mathrm{M}$ testosterone & $20 \cdot 5 \pm 5 \cdot 0^{*}$ & $99 \pm 6 \cdot 9$ \\
\hline $10^{-9} \mathrm{M}$ testosterone & $35 \cdot 7 \pm 7 \cdot 6^{+}$ & $97 \pm 7 \cdot 7$ \\
\hline $10^{-8} \mathrm{M}$ testosterone & $26 \cdot 6 \pm 4 \cdot 3^{+}$ & $95 \pm 8 \cdot 9$ \\
\hline
\end{tabular}

${ }^{*} P<0.05$ and ${ }^{\dagger} P<0.01$ with respect to control.

${ }^{a} \mathrm{ECS}$ were incubated for $1 \mathrm{~min}$ in PRP with testosterone. PRP was quickly removed and platelet aggregation was measured as described in Material and Methods section. Results are expressed as percentage of inhibition of platelet aggregation with respect to control (EC plus vehicle) and represent the means of three independent experiments $(n=3)$.

${ }^{\mathrm{b}}$ Aliquots of PRP (without ECs) were incubated with the indicated concentrations of testosterone. Basal group received vehicle alone. Immediately after ADP was added, platelet aggregation was measured. Results are expressed as percentage with respect to basal aggregation and represent the average \pm s.D. of three independent experiments. 


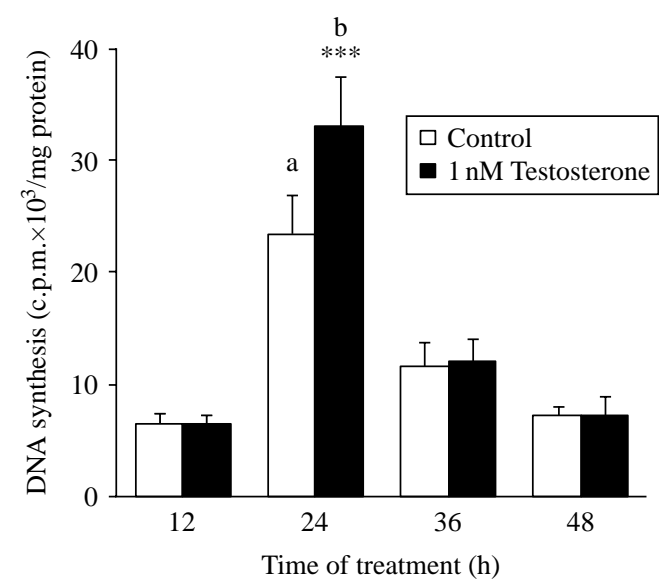

Figure 7 Effect of testosterone on $\left[{ }^{3} \mathrm{H}\right]$-thymidine incorporation. Subconfluent ECs were incubated in serum-free medium for $24 \mathrm{~h}$ and then treated with $1 \mathrm{nM}$ testosterone at the time indicated; $1 \mu \mathrm{Ci} / \mathrm{ml}$ of $\left[{ }^{3} \mathrm{H}\right]$-thymidine was added during the last $2 \mathrm{~h}$ of treatment. $\left[{ }^{3} \mathrm{H}\right]$-thymidine incorporation was measured as described in Materials and Methods section. Results are the average \pm s.D. of three independent experiments performed by quadruplicate. ${ }^{* * *} P<0 \cdot 001$ with respect to each control,

${ }^{\mathrm{a}} P<0.05$ vs all control groups, ${ }^{\mathrm{b}} P<0.05$ vs all testosterone groups.

involved in the hormonal effect. The participation of MAPK and PKC pathways in the nongenomic action of sex steroids on NOS activity has been reported (Rauschemberger et al. 2008, Cutini et al. 2009). It has been reported that PKC mediates testosterone and dihydrotestosterone relaxation in smooth muscle gallbladder (Kline \& Karpinski 2008). Indeed, it has also been described that DHEA directly regulates human eNOS activity through a nontranscriptional mechanism that depends on ERK/MAPK pathway (Simoncini et al. 2003). Taking in account that Raf kinase, the upstream activator of MEK kinase, might be phosphorylated by $\mathrm{PKC}$, we can hypothesize that the rapid action of testosterone on $\mathrm{NO}$ production requires the subsequent activation of PKC and MAPK systems. MAPK and PKC cascades have been involved in antiatherogenic and anti-inflammatory effects. Although some studies demonstrated that testosterone induces vasodilatation in an endothelium-dependent manner, several reports have shown that this nongenomic vasorelaxant action of androgen is endothelium independent (Perusquía \& Stallone 2010), mainly due to enhanced NO synthesis through the activation of nNOS in vascular smooth muscle. Therefore, at present we do not know whether the rapid effect of testosterone on signal transduction pathway activation, and endothelial NO production reported here, could be associated with any functional action on vascular wall. This will be the focus of future studies. However, we showed that the stimulation of NO synthesis elicited by testosterone is linked to a systemic action, the regulation of platelet activation, since $\mathrm{NO}$ release from the ECs modulates platelet aggregation.

EC proliferation and growth is critical to maintain vascular homeostasis, wound healing, and development. We found that testosterone increases rat aortic EC proliferation after $24 \mathrm{~h}$ of hormonal treatment and the mitogenic action declines substantially at $48 \mathrm{~h}$. The temporal profile of EC proliferation elicited by androgen exhibits a similar shape to control. Since ECs were obtained by primary culture, the decline in the mitogenic action of the steroid could be associated with the possibility that after $36-48 \mathrm{~h}$ of culture, the cells undergo differentiation and maturation, and under a low rate of proliferation, the hormone is unable to exert its mitogenic action. In future studies the effect of testosterone on EC differentiation markers will be assessed. Outside this, our findings are consistent with those reported by other authors who showed that testosterone increases EC growth in bovine aortic and in vein ECs (Williams et al. 2004). Indeed the adrenal androgen DHEA also promotes EC proliferation (Liu et al. 2008). NO has been proposed to be a physiological modulator of cell proliferation in several cells of different tissue origin. Although inhibition of cell growth appears to be the major effect exerted by $\mathrm{NO}$ in many cell types, mitogenic action of $\mathrm{NO}$ has also been described (Villalobo 2006). Here, we provide evidence that the proliferative effect of testosterone depends on NO production since the preincubation with the selective NOS inhibitor completely suppressed the action of androgen.

Using wound healing assays, we also demostrated that testosterone stimulates EC migration. It is known that EC proliferation and migration contribute to the development of new capillaries, event that requires the participation of vascular endothelial growth factor (VEGF). It has been reported that testosterone stimulates VEGF and NOS expression and promotes capillary formation in the cerebral

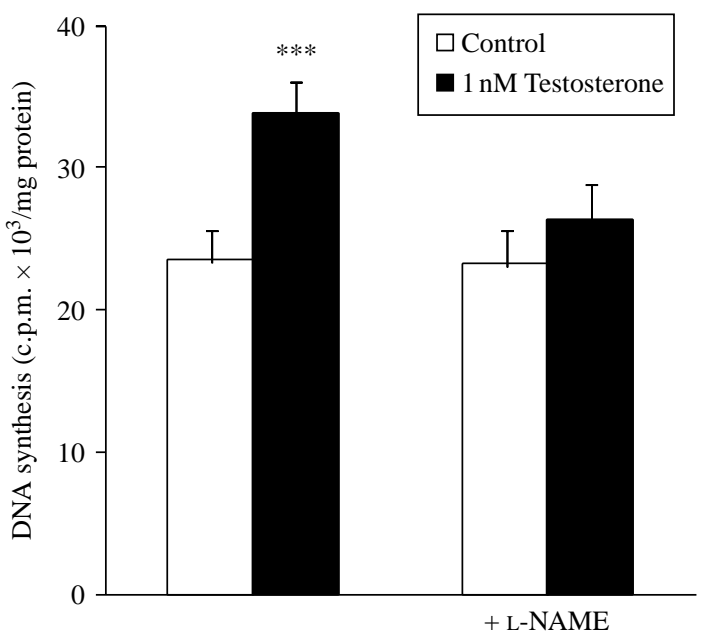

Figure 8 Effect of L-NAME on DNA synthesis induced by testosterone. Subconfluent ECs were incubated for $24 \mathrm{~h}$ in serumfree media, preincubated for $1 \mathrm{~h}$ with or without L-NAME $(1 \mu \mathrm{M})$, and then treated with testosterone for additional $24 \mathrm{~h}$.

$\left[{ }^{3} \mathrm{H}\right]$-thymidine incorporation was measured as described in Materials and Methods section. Results are the average \pm s.D. of three independent experiments $(n=4)$. ${ }^{* * *} P<0 \cdot 001$ with respect to control. 
(A)

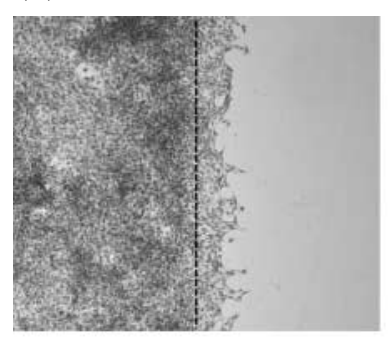

(B)

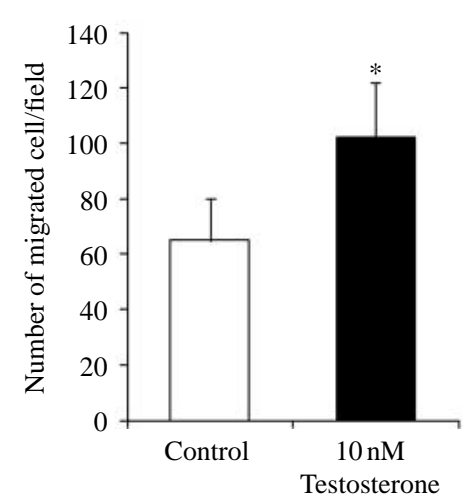

Figure 9 Effect of testosterone on EC migration. Confluent EC cultures were serum starved for $24 \mathrm{~h}$ and cells were removed by scraping. Detached cells were washed with PBS and the remaining monolayer was treated for $24 \mathrm{~h}$ with $10 \mathrm{nM}$ testosterone or vehicle. Dotted lines indicate the boundary between the unscratched and the scratched areas. (A) Images of representative fields of each condition after Giemsa staining $(40 \times)$. The scale line represents $350 \mu \mathrm{m}$. (B) Bars show mean \pm s.D. of number of migrated cells/field from three independent experiments performed by quadruplicate. ${ }^{*} P<0 \cdot 01$.

vascular system (Jesmin et al. 2004). In fact, in bovine aortic ECs, testosterone and DHEA promote EC proliferation, migration, and vascular tube formation, effects dependent on PTX-sensitive $G$ protein and ERK1/2 activation (Williams et al. 2004, Liu et al. 2008). Future studies will be conducted in order to address the possibility that the mitogenic action of testosterone could be associated with a putative androgen promotion of angiogenesis.

Immediately after synthesis, endothelial NO triggers two different effects: it translocates to smooth muscle tunica and induces GMPc-dependent vasorelaxation and may be released into the lumen and inhibited platelet aggregation (Ignarro et al. 1999, Förstermann 2010). We observed that the treatment of ECs with different concentrations of testosterone significantly inhibits platelet aggregation over control (ECs without hormonal treatment). The ability of the steroid to inhibited platelet aggregation depends on the presence of the endothelium. When PRP was incubated in the absence of ECs, there was no direct effect of testosterone on ADPinduced platelet aggregation. We showed that the antiplatelet activity of testosterone was related in part to the stimulation of $\mathrm{NO}$ production. In ECs that are unable to synthesize $\mathrm{NO}$ due to the presence of L-NAME, the antiaggregatory activity of the hormone was reduced. Altogether these data suggest that at the endothelial level, testosterone acutely increases NO liberation and consequently contributes to inhibit platelet aggregation.

In summary, the data presented contribute to the understanding of the transduction mechanism of testosterone on vascular tissue. The hormonal action not only implies the modulation of the synthesis of vasodilators, but also involves the vascular regulation of platelet aggregation process, both events are tightly associated with the prevention of atherosclerotic degeneration. The evidence provided support the hypothesis that EC behavior could be modulated not only by $E_{2}$ but also by other sex steroids. Since our results were obtained mainly using in vitro assays with isolated cells, the whole contribution of testosterone to vascular homeostasis cannot be addressed. Vascular health depends on the integration of cellular responses from blood cells (leukocytes and platelets), ECs, and muscle cells, so that at present it is difficult to draw a parallel between our results and the in vivo situation. Moreover, cross-talk between the biochemical action of testosterone and of other vascular agonists may also occur. The role of testosterone in female vascular beds and its physiological relevance will be focused in future investigations.

\section{Declaration of interest}

The authors declare that there is no conflict of interest that could be perceived as prejudicing the impartiality of the research reported.

\section{Funding}

This research was supported by grants from the SGCyT, Universidad Nacional del Sur, Argentina (PGI 24/B159); Consejo Nacional de Investigaciones Científicas y Técnicas (CONICET, Argentina, PIP N ${ }^{\circ}$ 0356). A E C and $\mathrm{P} \mathrm{H} \mathrm{C}$ are recipient of graduate and postdoctoral fellowship from CONICET respectively.

\section{References}

Bachetti T \& Morbidelli L 2000 Endothelial cells in culture: a model for studying vascular functions. Pharmacological Research 42 9-19. (doi:10.1006/ phrs.1999.0655)

Cooke JP \& Dzau VJ 1997 Nitric oxide synthase: role in genesis of vascular disease. Annual Review of Medicine 48 489-509. (doi:10.1146/annurev.med. 48.1.489)

Cutini P, Sellés J \& Massheimer V 2009 Cross-talk between rapid and long term effects of progesterone on vascular tissue. Journal of Steroid Biochemistry and Molecular Biology 115 36-43. (doi:10.1016/j.jsbmb.2009.02.014)

Duckles SP \& Miller VM 2010 Hormonal modulation of endothelial NO production. Pflügers Archiv: European Journal of Physiology 459 841-851. (doi:10.1007/s00424-010-0797-1)

Falkenstein E, Tillmann HC, Christ M, Feuring M \& Wehling M 2000 Multiple actions of steroid hormones - a focus on rapid, nongenomic effects. Pharmacological Reviews 52 513-556.

Farhat MY, Lavigne MC \& Ramwell PW 1996 The vascular protective effects of estrogen. FASEB Journal 10 615-624. 
Förstermann U 2010 Nitric oxide and oxidative stress in vascular disease. Pfligers Archiv: European Journal of Physiology 459 923-939. (doi:10.1007/ s00424-010-0808-2)

Goglia L, Tosi V, Sanchez AM, Flamini MI, Fu XD, Zullino S, Genazzani AR \& Simoncini T 2010 Endothelial regulation of eNOS, PAI-1 and t-PA by testosterone and dihydrotesterone in vitro and in vivo. Molecular Human Reproduction 16 761-769. (doi:10.1093/molehr/gaq049)

Gryglewski RJ, Palmer RM \& Moncada S 1986 Superoxide anion is involved in the breakdown of endothelium-derived vascular relaxing factor. Nature 320 454-456. (doi:10.1038/320454a0)

Han G, Ma H, Chintala R, Miyake K, Fulton DJ, Barman SA \& White RE 2007 Non genomic, endothelium-independent effects of estrogen on human coronary smooth muscle are mediated by type I (neuronal) NOS and PI3-kinase-Akt signalling. American Journal of Physiology. Heart and Circulatory Physiology 293 H314-H321. (doi:10.1152/ajpheart.01342.2006)

Harrison DG, Widder J, Grumbach I, Chem W, Weber M \& Searles C 2006 Endothelial mechanotransduction, nitric oxide and vascular inflammation. Journal of Internal Medicine 259 351-363. (doi:10.1111/j.1365-2796.2006. 01621.x)

Hsia J, Langer RD, Manson JE, Kuller L, Johnson KC, Hendrix SL, Pettinger M, Heckbert SL, Greep N, Crawford S et al. 2006 Conjugated equine estrogens and coronary heart disease: the Women's Health Initiative. Archives of Internal Medicine 166 357-365. (doi:10.1001/archinte.166.3.357)

Ignarro LJ 1989 Biological actions and properties of endothelium-derived nitric oxide formed and released from artery and vein. Circulation Research $651-21$.

Ignarro LJ, Cirino G, Casini A \& Napoli C 1999 Nitric oxide as a signaling molecule in the vascular system: an overview. Journal of Cardiovascular Pharmacology 34 879-886. (doi:10.1097/00005344-199912000-00016)

Jesmin S, Togashi H, Sakuma I, Mowa CN, Ueno K, Yamaguchi T, Yoshioka M \& Kitabatake A 2004 Gonadal hormones and frontocortical expression of vascular endothelial growth factor in male stroke-prone, spontaneously hypertensive rats, a model for attention-deficit/hyperactivity disorder. Endocrinology 145 4330-4343. (doi:10.1210/en.2004-0487)

Jones RD, English KM, Pugh PJ, Morice AH, Jones TH \& Channer KS 2002 Pulmonary vasodilatory action of testosterone: evidence of a calcium antagonistic action. Journal of Cardiovascular Pharmacology 39 814-823. (doi:10.1097/00005344-200206000-00006)

Jones RD, English KM, Jones TH \& Channer KS 2004 Testosterone-induced coronary vasodilatation occurs via a non-genomic mechanism: evidence of a direct calcium antagonism action. Clinical Science 107 149-158. (doi:10.1042/CS20030386)

Kanno K, Hirata Y, Imai T, Iwashina M \& Marumo F 1994 Regulation of inducible nitric oxide synthase gene by interleukin-1 beta in rat vascular endothelial cells. American Journal of Physiology 36 H2318-H2324.

Kikuta K, Sawamura T, Miwa S, Hashimoto N \& Masaki T 1998 High-affinity arginine transport of bovine aortic endothelial cells is impaired by lysophosphatidylcholine. Circulation Research 83 1088-1096.

Kline LW \& Karpinski E 2008 Testosterone and dihydrotestosterone inhibit gallbladder motility through multiple signalling pathways. Steroids $\mathbf{7 3}$ 1174-1180. (doi:10.1016/j.steroids.2008.05.006)

Knowles RG \& Moncada S 1994 Nitric oxide synthases in mammals. Biochemical Journal 298 249-258.

Koledova VV \& Khalil RA 2007 Sex hormone replacement therapy and modulation of vascular function in cardiovascular disease. Expert Review of Cardiovascular Therapy 5 1-13. (doi:10.1586/14779072.5.4.777)

Li J \& Al-Azzawi F 2009 Mechanism of androgen receptor action. Maturitas 63 142-148. (doi:10.1016/j.maturitas.2009.03.008)

Ling S, Dai A, Williams MR, Myles K, Dilley RJ, Komesaroff PA \& Sudhir K 2002 Testosterone enhances apoptosis related damage in human vascular endothelial cells. Endocrinology 143 1119-1125. (doi:10.1210/en.143.3. 1119)

Liu J, Hughes TE \& Sessa WC 1997 The first 35 amino acids and fatty acylation sites determine the molecular targeting of endothelial nitric oxide synthase into the Golgi region of cells: a green fluorescent protein study. Journal of Cell Biology 137 1525-1535. (doi:10.1083/jcb.137.7.1525)

Liu PY, Death AK \& Handelsman DJ 2003 Androgens and cardiovascular disease. Endocrine Reviews 24 313-340. (doi:10.1210/er.2003-0005)
Liu D, Iruthayanathan M, Homan L, Wang Y, Yang L, Wang Y \& Dillon J 2008 Dehydroepiandrosterone stimulates endothelial proliferation and angiogenesis through extracellular signal regulated kinase 1/2-mediated mechanisms. Endocrinology 149 889-898. (doi:10.1210/en.2007-1125)

Lowry OH, Rosebrough NJ, Farr AL \& Randall RJ 1951 Protein measurement with the Folin phenol reagent. Journal of Biological Chemistry $195265-277$.

Miller VM \& Mulvagh SL 2007 Sex steroids and endothelial function: translating basic science to clinical practice. Trends in Pharmacological Sciences 28 263-270. (doi:10.1016/j.tips.2007.04.004)

Miller VM \& Duckles SP 2008 Vascular actions of estrogens: functional implications. Pharmacological Reviews 60 210-241. (doi:10.1124/pr.107. 08002)

Moncada S \& Higgs EA 2006 Nitric oxide and the vascular endothelium. Handbook of Experimental Pharmacology 176 213-254.

Moreno PR, Sanz J \& Fuster V 2009 Promoting mechanisms of vascular health: circulating progenitor cells, angiogenesis, and reverse cholesterol transport. Journal of the American College of Cardiology 53 2315-2323. (doi:10.1016/j.jacc.2009.02.057)

Mukherjee TK, Dinh H, Chaudhuri G \& Nathan L 2002 Testosterone attenuates expression of vascular cell adhesion molecule- 1 by conversion to estradiol by aromatase in endothelial cells: implications in atherosclerosis. PNAS 99 4055-4060. (doi:10.1073/pnas.052703199)

Ouyang P, Michos ED \& Karas RH 2006 Hormone replacement therapy and the cardiovascular system lessons learned and unanswered questions. Journal of the American College of Cardiology 47 1741-1753. (doi:10.1016/j. jacc.2005.10.076)

Perusquía M \& Stallone JN 2010 Do androgens play a beneficial role in the regulation of vascular tone? Nongenomic vascular effects of testosterone metabolites American Journal of Physiology. Heart and Circulatory Physiology 298 H1301-H1307. (doi:10.1152/ajpheart.00753.2009)

Polini N, Rauschemberger MB, Mendiberri J, Selles J \& Massheimer V 2007 Effect of genistein and raloxifene on vascular dependent platelet aggregation. Molecular and Cellular Endocrinology 267 55-62. (doi:10.1016/j. mce.2006.12.037)

Qiao X, Mcconnell KR \& Khalil RA 2008 Sex steroids and vascular responses in hypertension and aging. Gender Medicine 5 S46-S64. (doi:10.1016/j. genm.2008.03.006)

Rauschemberger MB, Sellés J \& Massheimer V 2008 The direct action of estrone on vascular tissue involves genomic and non-genomic actions. Life Sciences 82 115-123. (doi:10.1016/j.lfs.2007.10.020)

Rowell KO, Hall J, Pugh PJ, Jones TH, Channer KS \& Jones RD 2009 Testosterone acts as an efficacious vasodilator in isolated in isolated human pulmonary arteries and veins: evidence for a biphasic effect at physiological and supra-physiological concentrations. Journal of Endocrinological Investigation 32 718-773.

Sandoval MJ, Cutini PH, Rauschemberger MB \& Massheimer VL 2010 The soyabean isoflavone genistein modulates endothelial cell behaviour. British Journal of Nutrition 104 171-179. (doi:10.1017/ S0007114510000413)

Selles J, Polini N, Alvarez C \& Massheimer V 2005 Novel action of estrone on vascular tissue: regulation of NOS and COX activity. Steroids 70 251-256. (doi:10.1016/j.steroids.2004.10.012)

Simoncini T, Mannella P, Fornari L, Varone G, Caruso A \& Genazzani AR 2003 Dehydroepiandrosterone modulates endothelilal nitric oxide synthesis via direct genomic and nongenomic mechanisms. Endocrinology 144 3449-3455. (doi:10.1210/en.2003-0044)

Tep-areenan P, Kendall DA \& Randall MD 2002 Testosterone-induced vasorelaxation in the rat mesenteric arterial bed is mediated predominantly via potassium channels. British Journal of Pharmacology 135 735-740. (doi:10.1038/sj.bjp.0704522)

Villalobo A 2006 Nitric oxide and cell proliferation. FEBS Journal 273 2329-2344. (doi:10.1111/j.1742-4658.2006.05250.x)

Villar I, Hobbs A \& Ahluwalia A 2008 Sex differences in vascular function: implication of endothelium-derived hyperpolarizing factor. Journal of Endocrinology 197 447-462. (doi:10.1677/JOE-08-0070)

White RE, Han G, Dimitropoulou C, Zhu S, Miyake K, Fulton D, Dave S \& Barman SA 2005 Estrogen-induced contraction of coronary arteries is 
mediated by superoxide generated in vascular smooth muscle. American Journal of Physiology. Heart and Circulatory Physiology 289 H1468-H1475. (doi:10.1152/ajpheart.01173.2004)

Williams MR, Dawood T, Ling S, Dai A, Lew R, Myles K, Funder JW, Sudhir K \& Komesaroff PA 2004 Dehydroepiandrosterone increases endothelial cell proliferation in vitro and improves endothelial function in vivo by mechanisms independent of androgen and estrogen receptors. Journal of Clinical Endocrinology and Metabolism 89 4708-4715. (doi:10.1210/ jc.2003-031560)

Yu J, Akishita M, Ogawa S, Son B, Kato S, Ouchi Y \& Okabe T 2010 Androgen receptor-dependent activation of endothelial nitric oxide synthase in vascular endothelial cells: role of phosphatidylinositol 3-kinase/AKT pathway. Endocrinology 151 1822-1828. (doi:10.1210/en. 2009-1048)

Received in final form 6 January 2012

Accepted 26 January 2012

Made available online as an Accepted Preprint 26 January 2012 